\title{
The investigation of artificial and natural defects on the fatigue strength of vacuum-assisted high pressure die cast AlSi9Cu3(Fe) aluminum alloy
}

\author{
Péter Szalva ${ }^{1}$ and Imre Orbulov ${ }^{1}$ \\ ${ }^{1}$ Budapest University of Technology and Economics
}

April 28, 2021

\begin{abstract}
AlSi9Cu3(Fe) vacuum-assisted high pressure die cast (VPDC) specimens were investigated by experimental fatigue test and fracture mechanics approach. The aims of the investigations were (i) to evaluate the fracture resistance and (ii) to indirectly determine the threshold stress intensity value $(\Delta \mathrm{Kth})$ of casting alloy in uniaxial tension. The specimens were sorted into two groups: specimens with different size $(0.01-0.40 \mathrm{~mm} 2)$ natural defects, and specimens an additional artificial blind hole. The fatigue strength region was tested at $\mathrm{R}=-1$ stress ratio to 107 number of cycles to fracture. The fracture mechanics approach was applied to study the behavior of the small cracks by Kitagawa diagram, the defect size was taken into account by the Murakami's ([?]area) parameter. The fatigue strength values were 104.7 MPa for smooth specimen, 92.7 MPa for specimen with D0.3 artificial hole, and 87.2 MPa for specimen with D0.6 artificial hole at the prescribed cycles, respectively.
\end{abstract}

The investigation of artificial and natural defects on the fatigue strength of vacuum-assisted high pressure die cast AlSi9Cu3(Fe) aluminum alloy

Péter SZALVA ${ }^{*}$, Imre Norbert ORBULOV ${ }^{1,2}$

${ }^{1}$ Department of Materials Science and Engineering, Budapest University of Technology and Economics, Múegyetem rakpart 3., Budapest, 1111, Hungary

${ }^{2}$ MTA-BME Lendület Composite Metal Foams Research Group, Múegyetem rakpart 3., Budapest, 1111, Hungary

*Corresponding Author:szalva@eik.bme.hu

*Telephone number: +36-30-562 3912

*ORCID ID: 0000-0002-6562-6165

\section{Abstract}

AlSi9Cu3(Fe) vacuum-assisted high pressure die cast (VPDC) specimens were investigated by experimental fatigue test and fracture mechanics approach. The aims of the investigations were (i) to evaluate the fracture resistance and (ii) to indirectly determine the threshold stress intensity value $\left(\Delta \mathrm{K}_{\mathrm{th}}\right)$ of casting alloy in uniaxial tension. The specimens were sorted into two groups: specimens with different size $\left(0.01-0.40 \mathrm{~mm}^{2}\right)$ natural defects, and specimens an additional artificial blind hole. The fatigue strength region was tested at $\mathrm{R}=-1$ stress ratio to $10^{7}$ number of cycles to fracture. The fracture mechanics approach was applied to study the behavior of the small cracks by Kitagawa diagram, the defect size was taken into account by the Murakami's ([?]area) parameter. The fatigue strength values were 104.7 MPa for smooth specimen, 92.7 MPa 
for specimen with D0.3 artificial hole, and $87.2 \mathrm{MPa}$ for specimen with D0.6 artificial hole at the prescribed cycles, respectively.

\section{Keywords}

fatigue strength, fatigue fracture, Kitagawa-Takahashi diagram, Murakami's parameter, aluminum die cast alloy;

\section{Nomenclature}

E Young's modulus, GPa

$\mathrm{N}$ The number of cycles to failure, -

$2 \mathrm{~N}$ The number of reversals to failure, -

$\mathrm{R}$ Stress ratio, $\left(\mathrm{R}=\sigma_{\min } / \sigma_{\max }\right)$, -

UTS Ultimate tensile strength, MPa

$\mathrm{R}_{\mathrm{p} 0.2}$ Proof strength, $\mathrm{MPa}$

Tan Tangent modulus, MPa

$\checkmark$ Poisson's ratio, -

$\sigma_{\text {amp }}$ Stress amplitude, $\mathrm{MPa}$

$\sigma_{\max }$ Maximal stress, $\mathrm{MPa}$

$\sigma_{\min }$ Minimal stress, $\mathrm{MPa}$

$\sigma_{\text {LCLmax }}$ Local stress maximum, MPa

$\sigma_{\text {nom }}$ Nominal stress, $\mathrm{MPa}$

$\sigma_{\mathrm{f}}$ Fatigue strength coefficient, $\mathrm{MPa}$

$\Delta \sigma_{\mathrm{f}}$ Stress-based fatigue limit, MPa

b Fatigue strength exponent, -

$\mathrm{K}_{\mathrm{t}}$ Elastic stress concentration factor, -

$\Delta \mathrm{K}_{\mathrm{th}}$ Threshold stress intensity range, $\mathrm{MPa} \mathrm{m}^{0.5}$

$\Delta \mathrm{K}$ Stress intensity factor range, $\mathrm{MPa} \mathrm{m}^{0.5}$

[?]area Murakami's geometrical parameter, $\mathrm{mm}$

A Defect area, $\mathrm{mm}^{2}$

D Diameter of the hole, $\mathrm{mm}$

$\mathrm{h}$ Depth of the hole, $\mathrm{mm}$

w Width of specimen, mm

$\alpha$ Geometric factor, -

\section{Introduction}

Aluminum alloys become more and more important from the aspects of lightweight structures and good formability. The low density of the lightweight alloys is advantageous for eco-friendly vehicles (just to mention an even actual engineering problem, becoming more and more pronounced in the case of electric vehicles). Their relatively easy processability also provides benefits for the automotive industry (demanding 
for geometry optimized, complex parts produced in one (or a few) steps). High pressure die casting (HPDC) is a kind of casting technology providing a modern metal processing, which combines the before mentioned requirements and benefits. However, HPDC products are affected by different kind of defects such as gas pores, shrinkages and oxides [1]. These defects form due to the high-speed injection under high pressures that are resulting in high turbulence during mold filling [2]. Naturally, the appearance of these defects is affecting material properties negatively [3]. The small sized defects are almost unavoidable and originating from the features (high speed, turbulent flow, fast oxid layer formation, etc.) of the HPDC technique; however, there are a few opportunities to limit the presence and the size of the defects. One of these possibilities is the vacuum-assisted high pressure die casting (VPDC) process. In this technique, the amount of the entrapped gas during the casting process is significantly decreased by a vacuum-assistance system (reducing the pressure in the system, degassing and thus limiting the formation of gas bubbles) [4,5]. The formation of material discontinuity is quite frequent in castings, and it is not avoidable totally, even in the case of vacuum-assisted processing [6]. These flaws are usually appearing as material inhomogeneities like micro gas porosities or shrinkages, or sometimes unavoidable geometry changes (due to thermal shrinkage). The flaws not only reduce the area of the effective load bearing cross section, but they may also induce crack formation [7]. Flaw containing cast parts have lower toughness and lower fatigue strength [8]. In practice, the fatigue fractures occur at or in the near vicinity of stress concentrators, and these concentrators are often gas pores. The stress concentrators always cause local stress level increments $\left(\sigma_{\text {LCLmax }}\right)$ that can be higher than the nominal stress $\left(\sigma_{\text {nom }}\right)$. The ratio of these stresses is known as the stress concentration factor $\left(K_{t}\right)$, which depends on the specimen geometry and load mode.

A few techniques exist to investigate [9] the influence of cracks on the fatigue life from Peterson [10], Neuber [11], Heywood [12], Siebel and Stiller [13] by relative stress gradient (RSG). More recently, Kobayashi and Matsui $[14,15]$ confirmed the usability of Murakami's parameter to aluminum alloys as well. The criterion based on local stresses is more realistic [16]. The Kitagawa-Takahashi (KT) diagram was adopted to qualitatively handle the behavior of short cracks in the infinite life region [17]. The KT relation is a visual aid, and a graphical interpretation, that take into account the stress-based fatigue limit $\left(\Delta \sigma_{\mathrm{f}}\right)$ and the threshold stress intensity $\left(\Delta \mathrm{K}_{\mathrm{th}}\right)$ range to define a criterion for non-propagating cracks [18]. The relationship is giving information about the expected life-time of a part at the given stress range and about the allowable initial crack size of the defect (below which no crack propagation occurs). Based on the experimental test results, the limit for non-propagation crack zone was constructed for internal small cracks and external artificial defects, respectively. The defect size calculations were performed by Murakami's geometrical parameter ([?]area - the square root of the defect area projected onto a plane perpendicular to the applied stress) [19-23]. This condition allows calculating the maximum stress intensity factor (SIF) [24] along the front of the cracks. The fatigue limit of most materials is not the critical stress for crack initiation but the threshold stress for non-propagation of the crack, which was initiated from original cracks, defects or inhomogeneities [24].

The aims of the investigations presented here were (i) to evaluate the fracture resistance and (ii) to determine the threshold stress intensity value $\left(\Delta \mathrm{K}_{\mathrm{th}}\right)$ of cast $\mathrm{AlSi} 9 \mathrm{Cu} 3(\mathrm{Fe})$ alloy containing small sized natural and artificial defects in uniaxial tension.

\section{Materials and methods}

The die cast fatigue specimens were cast in a multi-cavity casting tool (Fig. 1.a). The casting mold was designed for various mechanical and microstructural test specimens. The cast material was a widely used Al-Si-Cu secondary aluminum alloy AlSi9Cu3(Fe) (EN AC 46000). The specimen set were cast from one dose of melt. The chemical composition of the cast was analyzed by using an X-ray fluorescence (XRF) analyzer and the result is listed in Table 1 . The reason for using VPDC for specimen production is the result of previous investigations $[4,5]$, where defect-free fatigue was detected in most cases.

Table 1. Chemical composition of AlSi9Cu3(Fe) 


\begin{tabular}{lllllllll}
\hline Elements (in wt\%) & $\mathrm{Si}$ & $\mathrm{Fe}$ & $\mathrm{Cu}$ & $\mathrm{Mn}$ & $\mathrm{Mg}$ & $\mathrm{Zn}$ & $\mathrm{Ti}$ & $\mathrm{Al}$ \\
\hline AlSi9Cu3(Fe) & 9.63 & 0.81 & 2.54 & 0.32 & 0.30 & 0.71 & 0.10 & bal. \\
\hline
\end{tabular}

Preliminary tensile tests were also performed on 3 specimens to determine the basic mechanical properties of the alloy. The measured material parameters of the alloy are the proof strength $\left(\mathrm{R}_{\mathrm{p} 0.2}=186.5 \pm 4.6 \mathrm{MPa}\right)$, the ultimate tensile strength (UTS $=325 \pm 3.5 \mathrm{MPa})$ and the elongation at fracture $(\mathrm{A}=2.8 \pm 0.1 \%)$.

The specimens were produced by an OMS 450 cold chamber die casting machine. The molten metal was degassed by gas bubbling filtration (GBF) with $15 \mathrm{Lmin}^{-1}$ (Nitrogen for $6 \mathrm{~min}$ ). The molten metal was dosed automatically at $700^{\circ} \mathrm{C}$ temperature. The elevated tool temperature was maintained by oil, circulated at $170^{\circ} \mathrm{C}$ by a Tool-Temp TT-390/2 machine. The casting parameters were calculated by flow analysis. The plunger speed was set to $0.19 \mathrm{~ms}^{-1}$ in the first phase and to $2.9 \mathrm{~ms}^{-1}$ in the second phase, respectively. The intensification pressure was 720 bars. The plunger diameter was $60 \mathrm{~mm}$ and the total air volume in the chamber was $517 \mathrm{~cm}^{3}$ from which the total air volume in the mold was $289 \mathrm{~cm}^{3}$. The vacuum-assistance pressure level was $100 \pm 20$ mbar, ensured by a VDS kinetic valve, the pressure was measured by Thyracont VD81 digital vacuum meter. All specimens were polished carefully (with Buehler silicon carbide grinding paper P180 mesh at $240 \mathrm{~min}^{-1}$, P400 mesh at $220 \mathrm{~min}^{-1}$, P600 mesh at $200 \mathrm{~min}^{-1}$ and P800 mesh at $150 \mathrm{~min}^{-1}$, for 1 min each step) leading to smooth surface, with the average surface roughness of $R_{a}=0.41 \pm 0.07 \mu \mathrm{m}$, measured by a Mitutoyo SJ-410 surface roughness tester. The specimen dimensions are defined in Fig. 1.b. All specimens were tested in T1 heat-treated condition: water-cooled after casting and natural aged.

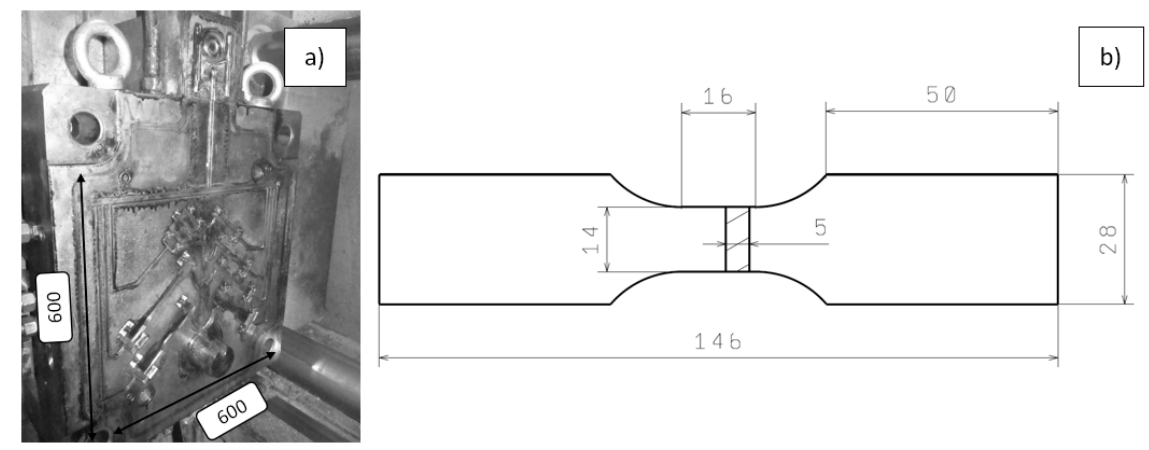

Fig. 1. Multi-cavity casting tool (a) and the design of the fatigue specimens and its dimensions (b).

The castings were preliminary tested by computed tomography (CT) to detect the unavoidable natural defects. The CT machine was a Phoenix v|tome|x c equipped with a cone-beam X-ray tube. The scanning was performed on the middle gauge area of the fatigue specimens. The resolution (based on the volume of the reconstructed smallest 3D element) was $25 \mu \mathrm{m}$. Porosity analysis was performed by Volume Graphic Studio Max 3.2 on the recorded CT images [25]. The results were used to investigate the highest porosity that can be considered. The fracture surfaces and their microscopic features were analyzed by light optical microscopy (LOM) on an Olympus BX51M microscope. In addition, the effect of the vacuum support on the porosity was also investigated on the fracture surface by scanning electron microscopy (SEM). The SEM was equipped with an energy dispersive X-ray analyser (EDX) the machine was a Zeiss Evo MA15 SEM $(\mathrm{EHT}=20 \mathrm{kV})$.

The detected highest pore (natural defect) in the outer layer of the specimens was $0.63 \pm 0.22 \mathrm{~mm}$. The natural defect area (the projection of the defects onto the plane perpendicular to the applied load direction) range was taken into account to define the geometry of the artificial defects. The smallest and the largest natural defect area were found to be $0.01 \mathrm{~mm}^{2}$ and $0.40 \mathrm{~mm}^{2}$, respectively. Therefore, the aim was to produce artificial defects with surface of $\sim 0.15 \mathrm{~mm}^{2}$ and $\sim 0.45 \mathrm{~mm}^{2}$ area, perpendicular to load direction. The artificial 
defects were produced by drilling, the diameter of the drilling tool was D0.3 $\mathrm{mm}$ or D0.6 $\mathrm{mm}$ in the case of small and large artificial defects, respectively. Based on these and on the required defect area sizes, the blind hole depths were set to $0.55 \mathrm{~mm}$ for the smaller and $0.70 \mathrm{~mm}$ for the larger diameter. (considering the $120^{\circ}$ tip angle of the drillers).

The modelled geometry is shown in Fig. 2.a. By the model, the effect of the artificial defects was considered. In the viewpoint of the elastic stress concentration factor, the smooth specimen was considered to have $\mathrm{K}_{\mathrm{t}}=1$. The elastic stress concentration factors $\left(\mathrm{K}_{\mathrm{t}}\right)$ of the artificial defects were calculated based on the results of the finite element method (FEM) model [26]. The FEM analyses were performed in Ansys. The element type was $2^{\text {nd }}$ order hexa- and tetra elements in the specimen and hexa elements in the whole clamping (Fig. 2.a). The number of the elements were 183.249 in the test piece and 18.415 in the fixture. The average element length was $2 \mathrm{~mm}$, the element length transition on the surface of the holes were set from 0.2 to 2 $\mathrm{mm}$. The affected distance of the influence volume was $2 \mathrm{~mm}$ (Fig. 2.b). The element sizes were selected after preliminary tests to avoid element size sensitivity [5]. The connection between the test specimen and the clamping was set to fixed contact. Bilinear material behavior was chosen, the material parameters were based on the measured and standard data $[27]$ of the aluminum alloy: $\mathrm{E}=73 \mathrm{GPa}, \nu=0.33, \mathrm{R}_{\mathrm{p} 0.2}=186.5 \mathrm{MPa}$ and $\mathrm{Tan}=4850 \mathrm{MPa}[5]$.

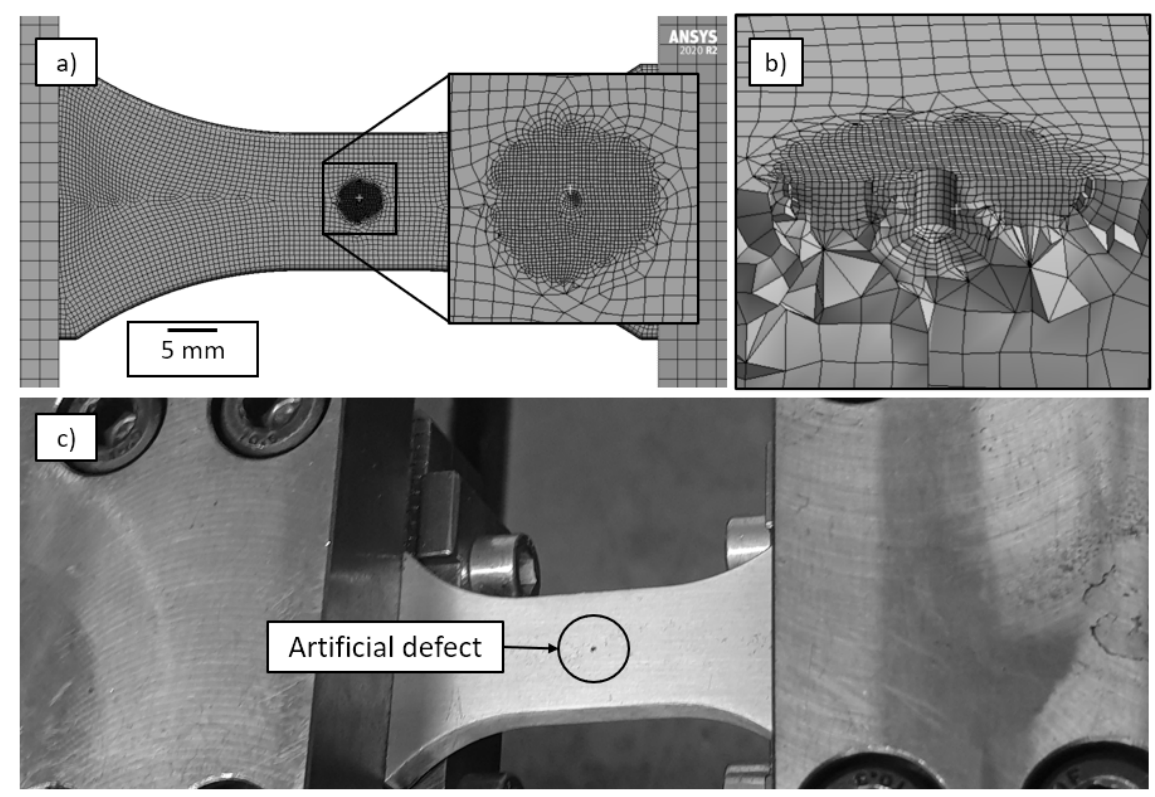

Fig. 2. Fatigue environment and FEM mesh (a); refined FEM mesh in the case of D0.6 mm blind hole (b) and real fatigue specimen in the fixture with D0.6 $\mathrm{mm}$ artificial hole in the middle of the specimen (c).

The fatigue tests have been performed on an Instron 8800 type servo-hydraulic testing machine, providing a maximum load of $63 \mathrm{kN}$. The uniaxial fatigue tests were run in load control. The frequency was $30 \mathrm{~Hz}$ with sinusoidal waveform, the stress ratio was set to $\mathrm{R}=-1$. The specimens were run to maximum $10^{7}$ number of cycles, and the specimens that did not break before this limit was considered run-out (surviving) specimens. The cycles to failure for each load level was evaluated by the two-parameter Weibull analysis approach [28]. The empirical S-N curve was described by the fitting of the power-law Basquin equation (Eq. 1.), by the least square method for the same confidence level of $50 \%$.

$\sigma_{\mathrm{amp}}=\sigma_{f}(2 N)^{b}$ (Eq. 1.)

where $\sigma_{\mathrm{f}}$ is the fatigue strength coefficient, $2 \mathrm{~N}$ representing the number of reversals to failure, and $\mathrm{b}$ is the fatigue strength exponent. 


\section{Results and Discussion}

\subsection{Elastic stress concentration factor $\left(K_{t}\right)$ and FEM analysis}

The fatigue fractures occur at small defects (material imperfections) or at around stress concentrators. These stress concentrators always cause local stress level increments $\left(\sigma_{\text {LCLmax }}\right)$ that can be (even many times) higher than the nominal stress level $\left(\sigma_{\text {nom }}\right)$, which would load the piece without the defect. The ratio of these stresses is known as the elastic stress concentration factor (Eq. 2.), which depends on the specimen geometry and on the load mode (tension, bending, etc.).

$K_{t}=\frac{\sigma_{\mathrm{LCL} \max }}{\sigma_{\text {nom }}}($ Eq. 2.)

where, $\mathrm{K}_{\mathrm{t}}$ is the elastic stress concentration factor, $\sigma_{\mathrm{LCLmax}}$ is the local maximal stress and $\sigma_{\text {nom }}$ is the nominal stress. The shape of the artificial defect is simple, its surface is considered to be the projection of the defect perpendicular to the load, according to the Murakami's approach [16]. However, the value of the elastic stress concentration factor is important; therefore, it was estimated by FEM calculations. Based on the investigation of Murat and Toktas [26], there is a geometry ratio (the hole diameter divided by the width of the specimen) threshold value (0.042), below which all analytical model (regression analysis [29], artificial neutral network [30], finite element analysis [31], etc.) solutions resulted in very similar $\mathrm{K}_{\mathrm{t}}$ values. Since the ratio of the artificial defect diameter (D0.3 mm or D0.6 mm) and the width of specimen $(14 \mathrm{~mm})$ is less than the 0.042 limit, the FEM result is reliable as the value of elastic stress concentration factor. The FEM analysis were run at $7.5 \mathrm{kN}$ at each hole diameter, the calculated nominal stress was $115.4 \mathrm{MPa}$ with the nominal cross-section of $65 \mathrm{~mm}^{2}$. The maximum of the equivalent von-Mises stress was $214.0 \mathrm{MPa}$ for the D0.3 mm (Fig. 3.a), and 227.7 MPa for the D0.6 mm holes (Fig. 3.b), respectively. The calculated elastic stress concentration factors were $\mathrm{K}_{\mathrm{t} D 0.3}=1.85$ and $\mathrm{K}_{\mathrm{t} \mathrm{D} 0.6}=1.97$, respectively.

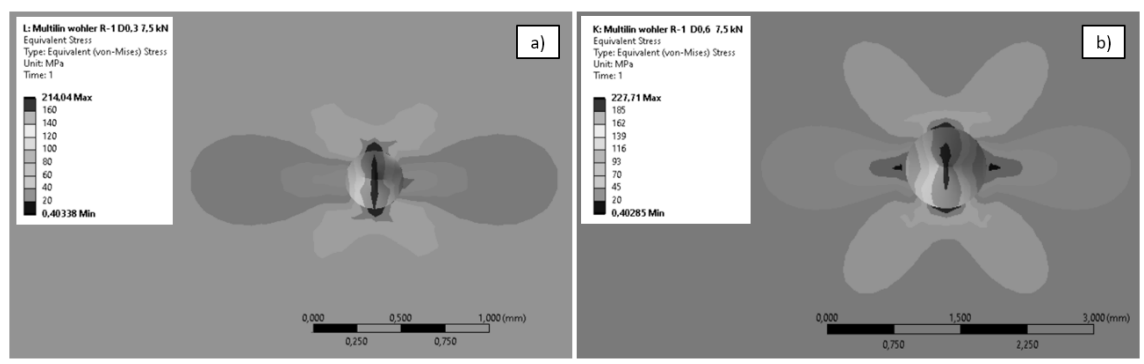

Fig. 3. FEM analysis: top view of the stress field in case of D0.3 $\mathrm{mm}$ hole (a) and top view of the stress field in case of D0.6 mm hole.

The artificial defect can be considered as a circular crack, the sharpness of the crack is the radius of curvature at the crack tip (d/2 in our case), and the crack length (2a) is a diameter (d) of the artificial hole. The artificial defects were produced by drilling, the hole radii were $0.15 \mathrm{~mm}$ (for D0.3 mm holes) and $0.30 \mathrm{~mm}$ (for the D0.6 mm holes), respectively. Although these looks like a blunt crack, they are comparable in size with the natural casting defects.

The LOM and SEM investigations proved that the fracture involved the artificial defects in all cases (examples are shown in Fig. 4). The cracks were initiated at the artificial defects and subsequently propagated. Initially, the crack growth was slow (I.), until it became critical in length (II.), at which point the crack became unstable (III.) (Fig. 4.b). The fish-eyed crack transition zone proved this phenomenon, the fronts of the blunting of the crack peaks were marked with dashed lines (Fig. 4.). 

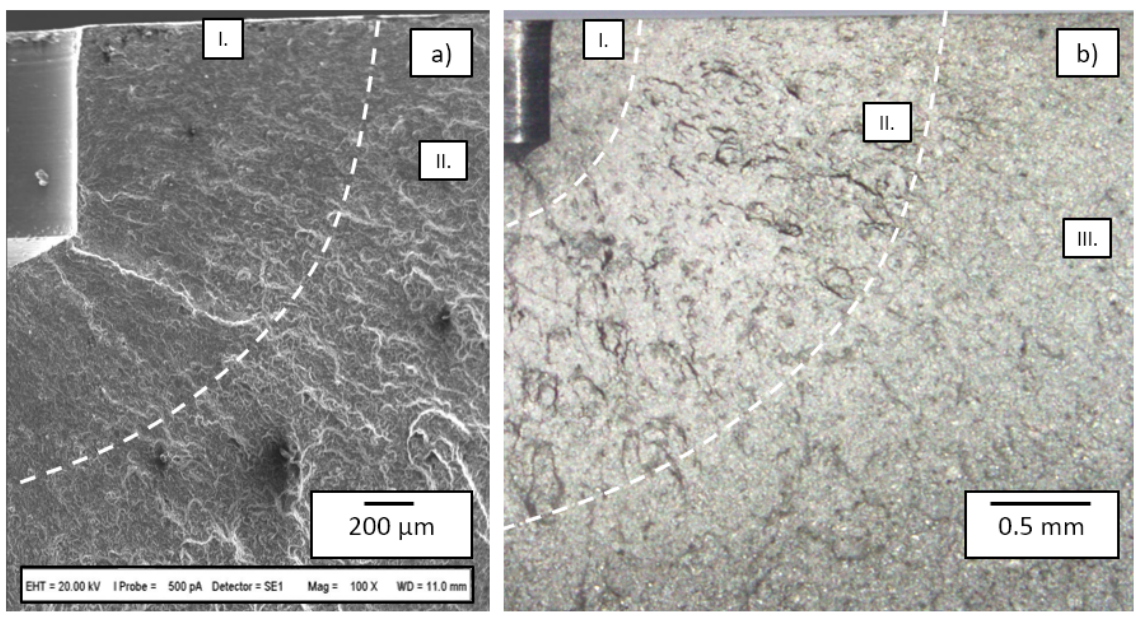

Fig. 4. Microscopic examination: SEM micrograph of a D0.6 $\mathrm{mm}$ hole at the fracture surface (a) and LOM micrograph about fish-eye transition zones at the fracture (b).

\subsection{Fatigue tests - experimental data}

The classic S-N diagram shows the relationship between stress-amplitude and cycle to failure. The curves displayed on log-log plots, and the represented data plot is the mean value of several test. The aluminum S-N curve continuously decreasing and does not exhibit well-defined endurance or fatigue limit [32]. The infinite region of the aluminum S-N curve is known as fatigue strength, where a specified number of cycles defines a given stress level. The fatigue strength is not a parameter independent material property, there is an influence of stress ratios, surface finish, notch sensitivity, etc. [19].

The results of the fatigue tests are shown in the log-log S-N diagram (Fig. 5). The presented curves were plotted for each $\mathrm{K}_{\mathrm{t}}$ value of the smooth specimens and the specimens with D0.6 mm and D0.3 mm artificial defects. The corresponding $\mathrm{K}_{\mathrm{t}}$ values are 1.00, 1.97 and 1.85, respectively. Curves (Basquin relationship, eq. 1.) were fitted on the measured points by the least square method at the confidence level of $50 \%$. The fitted curves are represented by straight lines in the log-log plots. The slope of the S-N curves determined the fatigue strength exponent (b) for each tested series. The intersection of the fitted curves with the vertical axis defined the fatigue strength coefficients $\left(\sigma_{\mathrm{f}}\right)$. All the parameters are listed in Table 2. 


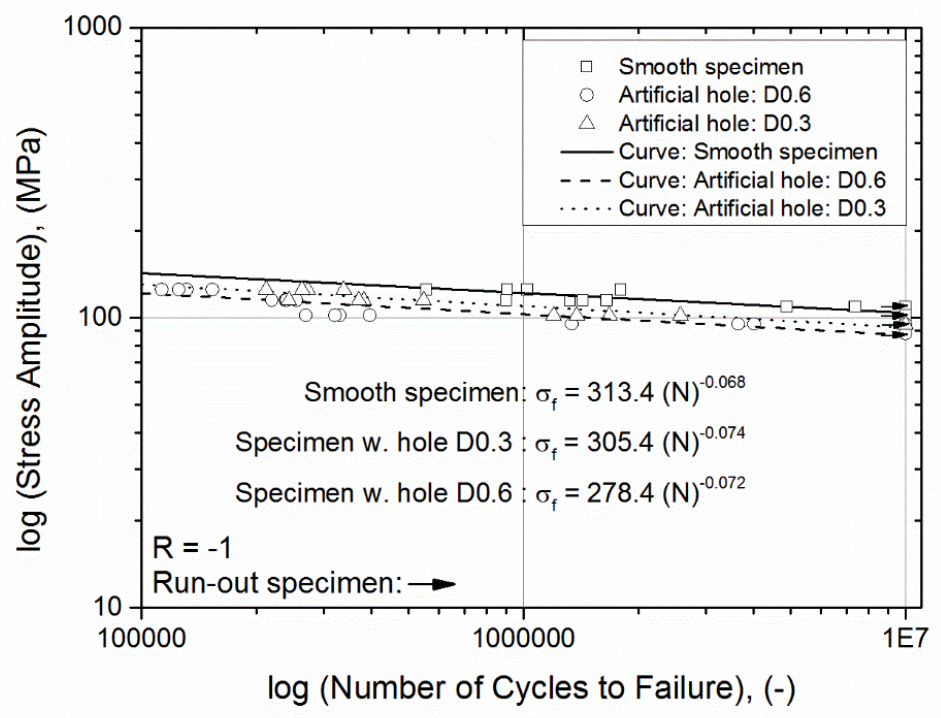

Fig. 5. The $\mathrm{S}-\mathrm{N}$ curves of the investigated VPDC cast specimens at stress asymmetry factor of $\mathrm{R}=-1$, at the reliability of $50 \%$, with the corresponding $\mathrm{K}_{\mathrm{t}}$ values of $1.00,1.97$, and 1.85 , respectively.

The calculated fatigue strengths for each specimen set at $10^{7}$ cycles (since $\mathrm{Al}$ alloys has no real fatigue limit) were 104.7 MPa for the smooth $\left(\mathrm{K}_{\mathrm{t}}=1.00\right)$ specimens, $92.7 \mathrm{MPa}$ for $\mathrm{K}_{\mathrm{t}} \mathrm{D} 0.3=1.85$ specimens, and $87.2 \mathrm{MPa}$ for $\mathrm{K}_{\mathrm{t} \text { D0.6 }}=1.97$ specimens, respectively. These results are also listed in Table 2 .

Table 2. Calculated results based on the fatigue tests

\begin{tabular}{lllll}
\hline Specimen type & $\mathrm{K}_{\mathrm{t}}(-)$ & Strength coefficient $(\mathrm{MPa})$ & Strength exponent $(-)$ & Fatigue strength at $10^{7}$ cycles $(\mathrm{MPa})$ \\
\hline Smooth spec. & 1.00 & 313.4 & -0.068 & 104.7 \\
Artificial hole D0.3 & 1.85 & 305.4 & -0.074 & 92.7 \\
Artificial hole D0.6 & 1.97 & 278.4 & -0.072 & 87.2 \\
\hline
\end{tabular}
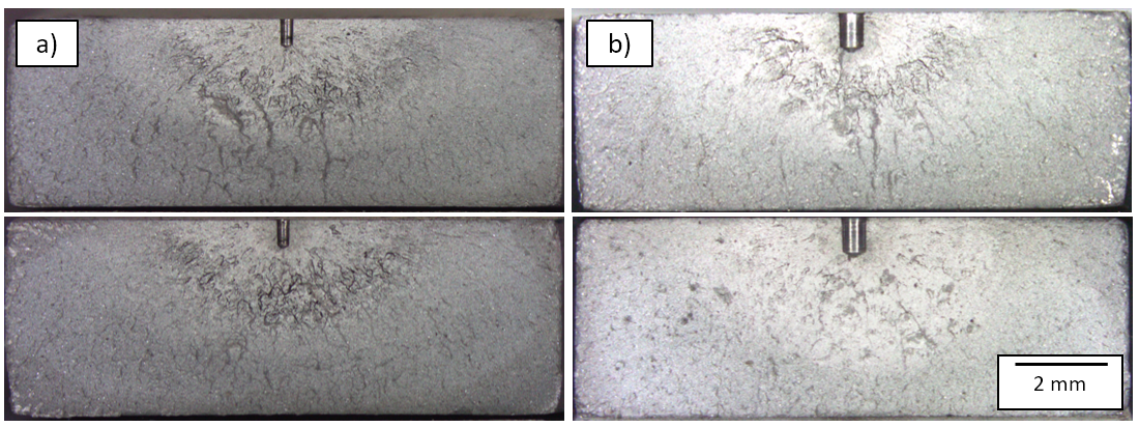

Fatigue strength decreased in the whole investigated fatigue life cycle range (up to $10^{7}$ cycles), in accordance with the literature. All run-out specimens were tested by dye penetrant process, but visible crack initiation was not detected. The fracture surfaces were proved the advantage of the applied vacuum-support investigated by LOM, because visible pores were not detected (Fig. 6.). 
Fig. 6. LOM photographs of the fracture surface of fatigue specimens: specimens with D0.3 artificial defects (a) and specimens with D0.6 artificial defects (b).

\subsection{Influence of the defect size}

In practice, the fatigue fractures occur in most cases at around stress concentrators, like natural internal defects and artificial surface defects in this study. The geometry of the pores that caused fractures were mainly spherical. The sphericity of these pores is defined by the shape factor (2.6-6.2) and detected by $\mu \mathrm{CT}$ before fatigue test. The natural stress concentrators were mainly gas pores in the area range from $0.010 \mathrm{~mm}^{2}$ to $0.403 \mathrm{~mm}^{2}$, typically located below the outer fine grain layer $(0.63 \pm 0.22 \mathrm{~mm}$ depth from the surface). In the case of run-out fatigue specimens the detected highest pore below the outer layer was taken into account as non-propagating crack. The detected pores in this layer were in the area ranges from $0.010 \mathrm{~mm}^{2}$ to $0.106 \mathrm{~mm}^{2}$. The detected natural defect area range in the fracture surface was taken into account to define of the geometry (depth for the given diameters) of the artificial defects that were $0.148 \mathrm{~mm}^{2}$ and $0.471 \mathrm{~mm}^{2}$, respectively.

The fatigue test results were further evaluated by the Kitagawa-Takahashi (KT) approach. The influence of defect size was taken into account by the square root of the projected [?]area (Murakami's parameter). The KT diagram was constructed on the basis of the experimental results. The stress intensity factor range $(\Delta \mathrm{K})$ was calculated in the given form (Eq. 3.) [20].

$\Delta K=\alpha \Delta \sigma \sqrt{\pi \sqrt{ } \text { area }}$ (Eq. 3).

where $\Delta \mathrm{K}$ is the stress intensity factor range, $\alpha$ is a geometric factor (depends on specimen size and the size of the crack), $\Delta \sigma$ is the stress range (function of the design and application), [?]area is the Murakami's parameter. The geometric factor of the internal defect was $\alpha_{\mathrm{int}}=0.5$, while for the surface defect it was $\alpha_{\text {surf }}=0.65[24,33]$.

It is important to note, if $\Delta \mathrm{K}$ is lower than a threshold stress intensity range value $\left(\Delta \mathrm{K}_{\mathrm{th}}\right)$, the crack will not propagate. In case of the materials, which have no exact fatigue limit (like $\mathrm{Al}$ alloys), the threshold stress intensity range is also not an exact value. The investigated aluminum alloy can be characterized by the fatigue strength, where the fatigue strength depends on the given number of cycles, and as a result the threshold stress intensity range value has similar features too. The KT diagram represents the influence of the defect size on the fatigue strength at a given number of cycles $\left(10^{7}\right.$ in our case, see Fig. 7.). This relation is represented in a log-log diagram, where the defect size (defect area) and the given fatigue limit (fatigue strength) are shown at a given number of cycles (Fig. 7.).

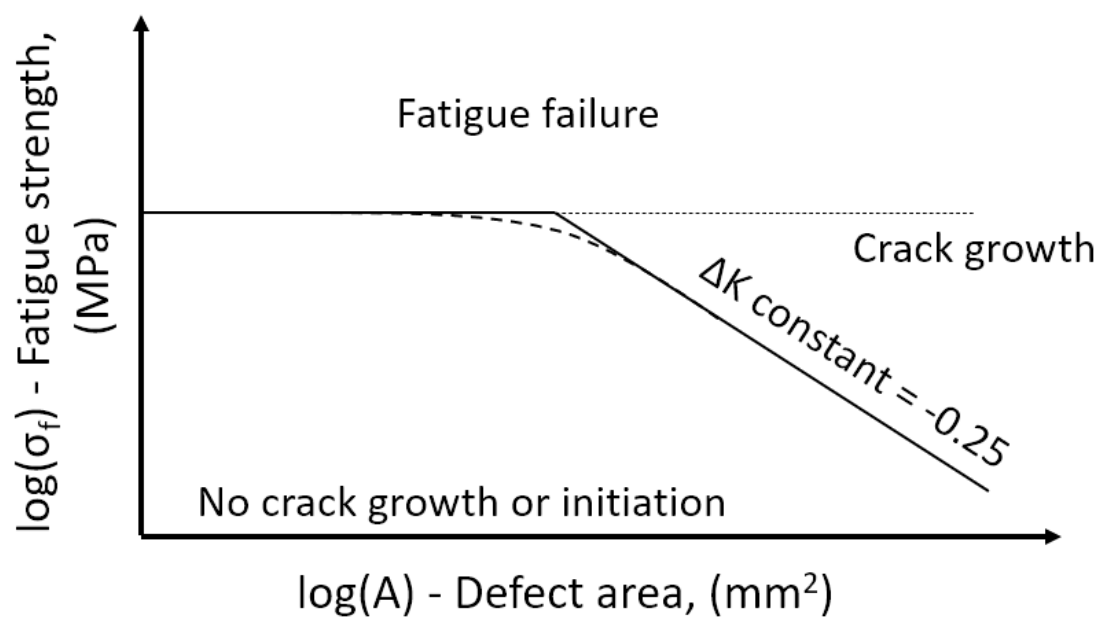


Fig. 7. Schematic diagram of Kitagawa-Takahashi (KT) diagram, represented in $\log \left(\sigma_{\mathrm{f}}\right)-\log ($ Area $)$ system.

The diagram shows two intersecting lines in the log-log coordinate system, where the horizontal part is defined by the fatigue strength and the monotonically decreasing part is representing the effect of increasing defect size. The slope of the monotonically decreasing part is constant, the slope of the curve is $-0.25[33,34]$. The area below the curve is safe. If the fatigue strength and defect area remain below the curve in Fig 7 ., then no crack initialization (or in the case of an existing crack no propagation) occurs. The area above the curve is unsafe and in this field fatigue crack initialization and propagation can occur (at the given reliability at which the fatigue strength was determined). The projected defect area is in $\mathrm{mm}^{2}$, and the calculated experimental fatigue strength is in MPa.

The fatigue test results were evaluated based on the fracture surfaces and at the failure stress level and represented in Fig. 8. If the fracture initiated from natural defect, the fracture was investigated by LOM and the defect was characterized by its surface. These points were marked by ' + ' signs in the diagram. If the fracture was initiated from the artificial surface defect the points were marked by 'o' signs. When pore was not detected in the fracture surface the biggest pore was considered in the outer fine-grained layer based on the CT results as a not initiated defect. In the case of run-out specimen the procedure was the same.

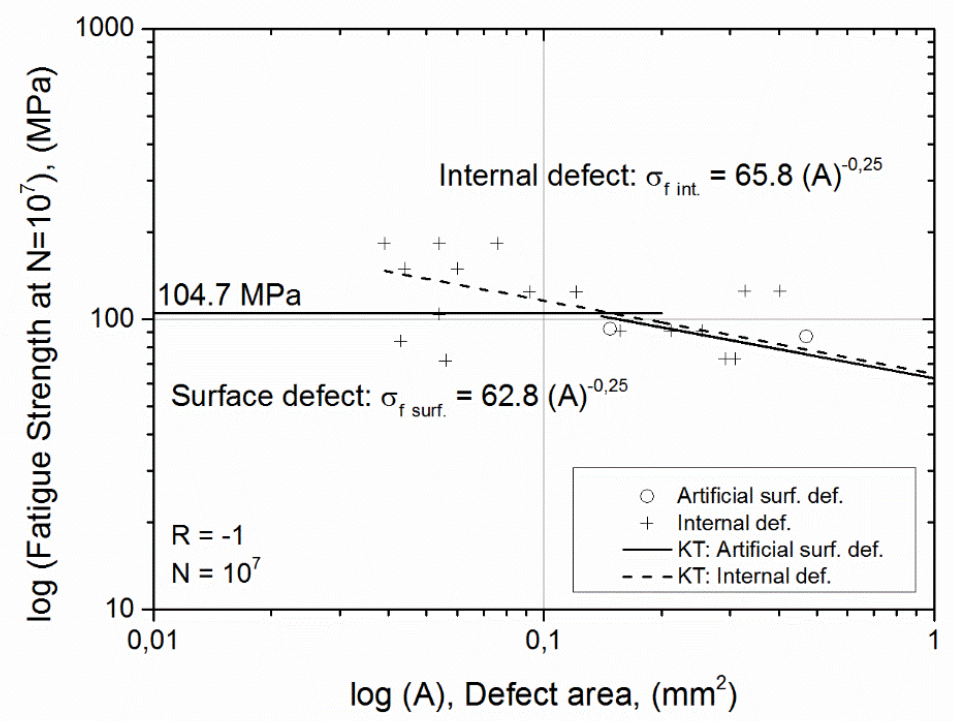

Fig. 8. The Kitagawa-Takahashi diagram based on the experimental data.

In this data-cloud the [?] area and $\sigma_{\text {amp }}$ value pairs were measured, and the threshold stress intensity range value $\left(\Delta \mathrm{K}_{\mathrm{th}}\right)$ was varied to fit the monotonically decreasing curve section according to the equation (Eq. 4.).

$\sigma_{\mathrm{amp}}=\underline{\Delta \mathrm{K}_{\tau n}}$

greek $\sqrt{\pi \sqrt{ } \text { area }}($ Eq. 4.)

The horizontal line section is representing the fatigue strength of the smooth specimens at $104.7 \mathrm{MPa}$ and at the given number of cycles $10^{7}$. The diagram includes the artificial surface defects and volumetric natural porosities too. The main advantage of this method is that the area of the defect is used, proving benefits when defects are varying in shape [34]. It is useful when the shape of the discontinuities is different. The Authors have to note that fatigue fracture did not occur in drilled castings by natural defect, in these cases, 
the fracture always initiated around the artificial defect. According to this evaluation method the calculated $\Delta \mathrm{K}_{\text {th }}$ value was found to be $1.8 \mathrm{MPa} \mathrm{m}^{0.5}$, this threshold stress intensity is an acceptable value, and it is in accordance with the literature. Based on the literature data, the threshold stress intensity value range of cast aluminum was reported between 0.98 and $1.80 \mathrm{MPa} \mathrm{m}^{0.5}[35,36,37]$. According to the calculated data, this value is closer to the more favorable upper limit, which is due to the smaller number of material discontinuity, proving the benefits of the VPDC method. On the other hand, the KT approach is proved to be a correct indirect method to determine the $\Delta \mathrm{K}_{\mathrm{th}}$ value of a material with less efforts compared to a standardized tests for stable crack propagation.

The constructed knee point is based on the mean values the fatigue strength begins to decline from the defect size larger than $0.16 \mathrm{~mm}^{2}$. This is a calculated defect area value, where the two curves intersect. If the diameter of the pore size is calculated with an equivalent sphere, the defect size (diameter) determined by the calculation would be $0.45 \mathrm{~mm}$. Although the knee point was constructed and calculated as the intersection of the lines, in the reality it is not an exact intersection point, but can be approximated more realistically by rounding (as shown by dashed line in Fig. 7.) and will be the part of further investigations.

The diagram in Fig. 8. shows that the surface defects are more dangerous than internal defects for fatigue fracture (the safe area is smaller). This fact agrees with the results reported in the literature, but the results are close to each other $\left(65.8 \mathrm{MPa} \mathrm{m}^{-0.25}\right.$ for internal natural defects and $62.8 \mathrm{MPa} \mathrm{m}^{-0.25}$ for artificial surface defects). Failure due to natural surface defect (opened to the surface) was not detected in the complete specimen set $(60 \mathrm{pcs})$ examined in this study. The close $\Delta \mathrm{K}_{\text {th }}$ values may also be explained by the fact

that the outer fine-grained layer is more favorable against crack propagation, as well as by that the internal defects are in a characteristic depth (at $0.63 \pm 0.22 \mathrm{~mm}$ ) outer layer.

\section{Conclusions}

In this study AlSi9Cu3(Fe) VPDC casting fatigue specimens were tested. The fatigue strength region was investigated at $\mathrm{R}=-1$ stress ratio at prescribed $10^{7}$ number of cycles to failure. The fracture mechanics approach for characterizing the influence of natural internal and artificial surface defects on the fatigue properties of VPDC aluminum AlSi9Cu3(Fe) alloy was employed. From the detailed investigations, the following conclusions can be drawn:

- The threshold stress intensity value $\left(\Delta \mathrm{K}_{\text {th }}\right)$ was determined successfully and found to be $1.8 \mathrm{MPa} \mathrm{m}^{0.5}$, that is in well agreement to the reported literature data.

- The KT approach is proved to be a correct indirect method to determine the $\Delta \mathrm{K}_{\mathrm{th}}$ value, in case of VPDC aluminum casting, when the defect characterized by the shape factor of these pores between 2.6-6.2, and detected area range between $0.01 \mathrm{~mm}^{2}$ to $0.40 \mathrm{~mm}^{2}$.

- The Kitagawa-Takahashi diagram can be used to investigate the influence of defect on the fatigue strength at $10^{7}$ number of cycles. The Murakami's parameter was used to consider the differences of defect shape and defect dimensions.

- The fatigue strength values were 104.7 MPa for smooth specimen, 92.7 MPa for specimen with D0.3 mm artificial hole, and 87.2 $\mathrm{MPa}$ for specimen with D0.6 mm artificial hole at the prescribed $10^{7}$ cycles, respectively.

- The fracture mechanics approach was also employed to investigate the critical measure of natural internal porosity. The critical defect size determined based on fracture mechanics approach is $0.16 \mathrm{~mm}^{2}$, the diameter of the equivalent spherical porosity is $0.45 \mathrm{~mm}$.

- The reduction in the number of inhomogeneities due to vacuum-assisted die casting has a positive effect on the fatigue strength, the threshold stress intensity range and the crack propagation, respectively.

\section{Acknowledgement}

The author would like to thank Dr. Tamás Rick, FÉMALK Co. for providing the fatigue specimens of the casting trials.

The research reported in this paper and carried out at BME has been supported by the NRDI Fund (TKP2020 
NC, Grant No. BME-NCS) based on the charter of bolster issued by the NRDI Office under the auspices of the Ministry for Innovation and Technology. The research reported in this paper and carried out at BME has been supported by the NRDI Fund (TKP2020 IES, Grant No. BME-IE-NAT) based on the charter of bolster issued by the NRDI Office under the auspices of the Ministry for Innovation and Technology.

The research reported in this paper has been supported by the KDP, Ministry of Innovation and Technology, and the National Research, Development and Innovation Fund.

Data availability

The raw data required to reproduce these findings cannot be shared at this time due to legal or ethical reasons.

\section{References}

[1] L. Lattanzi, A. Fabrizi, A. Fortini, M. Merlin, G. Timelli: Effect of microstructure and casting defects on the fatigue behavior of the high-pressure die-cast AlSi9Cu3(Fe) alloy, Procedia Structural Integrity, (2017), 505-512,http://doi.org10.1016/j.prostr.2017.11.119

[2] A. Ben Ahmed, M.I. Houria, R. Fathallah, H. Sidhom, The effect of interacting defects on the HCF behavior of Al-Si-Mg aluminum alloys, Journal of Alloys and Compounds, (2019), 779, 618629,https://doi.org/10.1016/j.jallcom.2018.11.282

[3] Antonio Rotella, Yves Nadot, Mickael Piellard, Rémi Augustin, Michel Fleuriot: Fatigue limit of a cast AlSi-Mg alloy (A357-T6) with natural casting shrinkages using ASTM standard X-ray inspection, International Journal of Fatigue, (2018), 114., 177-188.

https://doi.org/10.1016/j.ijfatigue.2018.05.026

[4] Szalva P., Orbulov I.N., Influence of vacuum support on the fatigue life of AlSi9Cu3(Fe) aluminum alloy die castings, Journal of Materials Engineering and Performance, 29., 9, 5685-5695., (2020) DOI: 10.1007/s11665020-05050-y

[5] Szalva P., Orbulov I.N., Fatigue testing and non-destructive characterization of AlSi9Cu3(Fe) die cast specimens by computer tomography, Fatigue \& Fracture of Engineering Materials \& Structures, 43, 9, 19491958 (2020) DOI: 10.1111/ffe.13249

[6] Shiozawa K., Thohda Y., Sun S-M., Crack initiation and small fatigue crack growth behaviour of squeezcast Al-Si aluminium alloys, Fatigue Fracture of Engineering Material Structures 20. 237-247. (1997)

[7] Hanxue Cao, Ziwei Luo, Chengcheng Wang, Jing Wang, Tao Hu, Lang Xiao, Junqi Che, The Stress Concentration Mechanism of Pores Affecting the Tensile Properties in Vacuum Die Casting Metals, Materials, 13. (2019), DOI: $10.3390 /$ ma13133019

[8] Dejan Tomazincic, Matej Borovinsek, Zoran Ren, Jermej Klemenc, Improved prediction of low-cycle fatigue life for high-pressure die-cast aluminium alloy AlSi9Cu3 with significant porosity, International Journal of Fatigue, 144., (2021),https://doi.org/10.1016/j.ijfatigue.2020.106061

[9] Yung-Li Lee, Jwo Pan, Richard B. Hathaway, Mark E. Barkey, Fatigue Testing and Analysis, ISBN 0-7506-7719-8, (2005), section 4.4.

[10] Peterson, R. E., Analytical approach to stress concentration effects in aircraft materials, U. S. Air Force - WADC Symposium on Fatigue Metals, Dayton, Ohio, Technical Report 59-507, (1959)

[11] Neuber, H., Theory of Notch Stress, J.W. Edwards, Ann Arbor, MI, (1946)

[12] Heywood, R. B., Designing Against Failure, Chapman \& Hall, London, (1962)

[13] Siebel, E. and Stieler, M., Significance of dissimilar stress distributions for cycling loading,

VDI-Z., Bd 97, No. 5, 121-126., (1955) 
[14] Kobayashi M., Matsui T., Prediction of fatigue strength of aluminum casting alloys by the [?]area parameter model, Trans. JSME, ser. A, 62., 594. 341-346., (1996)

[15] Murakami Y., Ikeda H., Toriyama T., Quantitative evaluation of effects of inhomogeneity phases on the fatigue strength of Al-Si new alloys, Proc.Int.Conf.Mech.Behavior Mater., ICM6, Kyoto (Japan), 433-438, (1991)

[16] P. Mu, Y. Nadot, I. Serrano-Munoz, , A. Chabod: Multiaxial fatigue design of cast parts: Influence of complex defect on cast AS7G06-T6, Engineering Fracture Mechanics, (2014), 131, 315328,https://doi.org/10.1016/j.engfracmech.2014.08.007

[17] Kitagawa H., Takahashi S., Applicability of fracture mechanics to very small cracks or cracks in the early stage. In: Proceedings of the second international conference on mech. behaviour of metals. ASM, 627-631, (1976)

[18] Ciavarella M., Monno F., On the possible generalization of the Kitagawa-Takahashi diagram and of the El Haddad equation of finite life, International Journal of Fatigue, 28., 1826-1837., (2006)

[19] P. Mu, Y. Nadot, C. Nadot-Martin, A. Chabod, I. Serrano-Munoz, C. Verdu: Influence of casting defects on the fatigue behavior of cast aluminum AS7G06-T6, International Journal of Fatigue, (2014), 63, 97-109,https://doi.org/10.1016/j.ijfatigue.2014.01.011

[20] Murakami Y., Effects of Small Defects and Nonmetallic Inclusion, Metal Fatigue, JSME, 1., (2002)

[21] Murakami Y., Materials defects as the basis of fatigue design, International Journal of Fatigue, 41., 2-10., (2012),https://doi.org/10.1016/j.ijfatigue.2011.12.001

[22] Yamashita Y., Murakami Y., Small crack growth model from low to very high cycle fatigue regime for internal fatigue failure of high strength steel, International Journal of Fatigue, 93., 406-414., (2016),https://doi.org/10.1016/j.ijfatigue.2016.04.016

[23] Krewerth D., Lippman T., Weidner A., Bierman H., Influence of non-metallic inclusions on fatigue life in the very high cycle fatigue regime, International Journal of Fatigue, 84., 40-52., (2016),https://doi.org/10.1016/j.ijfatigue.2015.11.001

[24] Murakami Y., Beretta S., Small Defects and Inhomogeneities in Fatigue Strength: Experient, Model and Statistical Implication, Extremes 2:2, 123-147. (1999)

[25] VG Studio MAX 3.2 Software (VG.034-EN.v03_B I 11.2014.), Volume Graphics GMBH, Heidelberg, Germany, 2014.;

[26] Murat Tolga Ozkan, Ihsan Toktas, Determination of the stress concentration factor $\left(\mathrm{K}_{\mathrm{t}}\right)$ in a rectangular plate with a hole under tensile stress using different methods, Fracture Mechanics and Modelling, 839-847, (2016)

[27] Dr.-Ing. Werner Hesse, Key to Aluminium Alloys, Aluminium-Verlag, Dusseldorf; 2008. p. 88

[28] D. Bin, J. Danyu, G. Jianghong, Is a three-parameter Weibull function really necessary for the characterization of the statistical variation of the strength of brittle ceramics?, Journal of the European Ceramic Society, 38/4. 2234-2242. (2018)

[29] Bas D., Boyaci I., Modeling and optimization, II. Comparison of estimation capabilities of response surface methodology with artificial neural networks in a biochemical reaction, J. Food Eng. 78, pp. 846-854, (2007)

[30] Ozkan M.T., Experimental and artificial neural network study of heat formation values of drilling \& boring operations on Al 7075 T6 workpiece, Indian Journal of Engineering \& Materials Science 20, 4, 259-268, (2013) 
[31] Ko-Ta C., Modeling and analysis of the effects of machining parameters on the performance characteristics in the EDM process of $\mathrm{Al}_{2} \mathrm{O}_{3}+\mathrm{TiC}$ mixed ceramic, International Journal of Advanced Manufacturing Technology 37, 523-533, (2008)

[32] Murakami Y., Endo M., Prediction equation for $\Delta \mathrm{K}_{\mathrm{th}}$ of various metals containing small defects in terms of the Vickers hardness (HV) and the square root of the projected area od defects, Fracture Mechanics 8., 105-124. (1990)

[33] Linder J., Arvidsson A., Kron J., The influence of porosity on the fatigue strength of high-pressure die cast aluminium, Fatigue Fract. Engng. Material Struct., 29. 357-363., (2006)

[34] Linder J., The influence of surrounding environment on the fatigue properties for a high pressure die cast AlSi9Cu3 alloy, Fatigue Fract. Engng. Material Struct., 30. 759-765., (2007)

[35] Antonio Rotella, Yves Nadot, Mickael Piellard, Rémi Augustin, Michel Fleuriot, Influence of defect morphology and position on the fatigue limit of cast $\mathrm{Al}$ alloy: 3D characterization by X-ray microtomography of natural and artificial defect, Material Science \& Engineering A, 785., (2020)

[36] Dabayeh A. A., Berube A. J., Topper T.H., An experimental study of the effect of a flow at a notch root on the fatigue life of cast Al 319., Int. J. Fatigue, 20., 517-530., (1998.)

[37] Ting J. C., Lawrence F. V., Modelling the long-life behaviour of a cast aluminium alloy, Fatigue Fracture of Engineering Material Structure, 16., 631-647., (1993.)

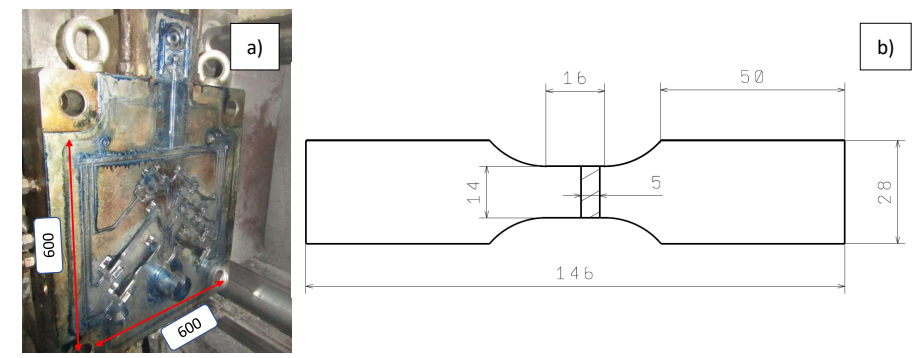



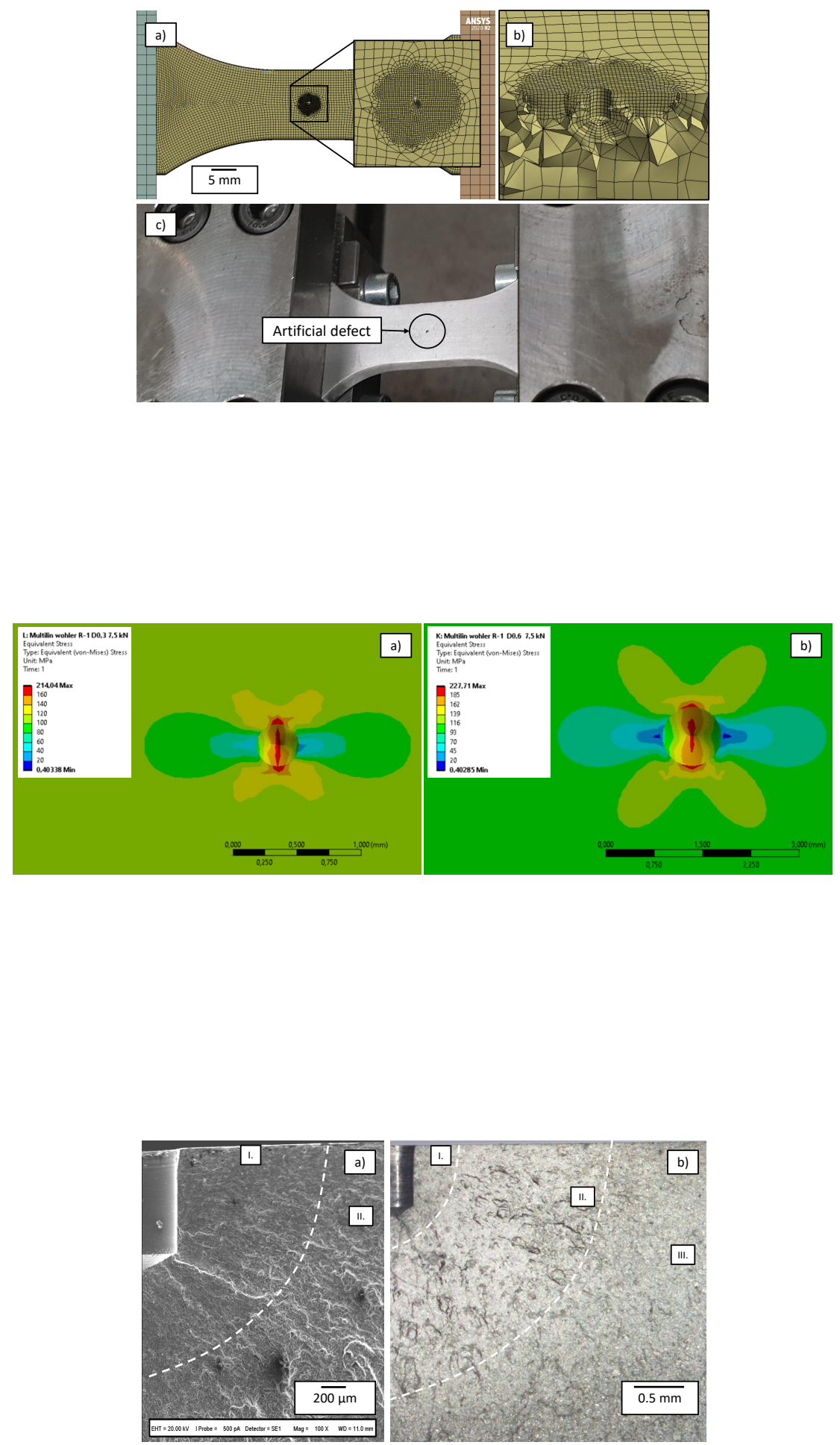

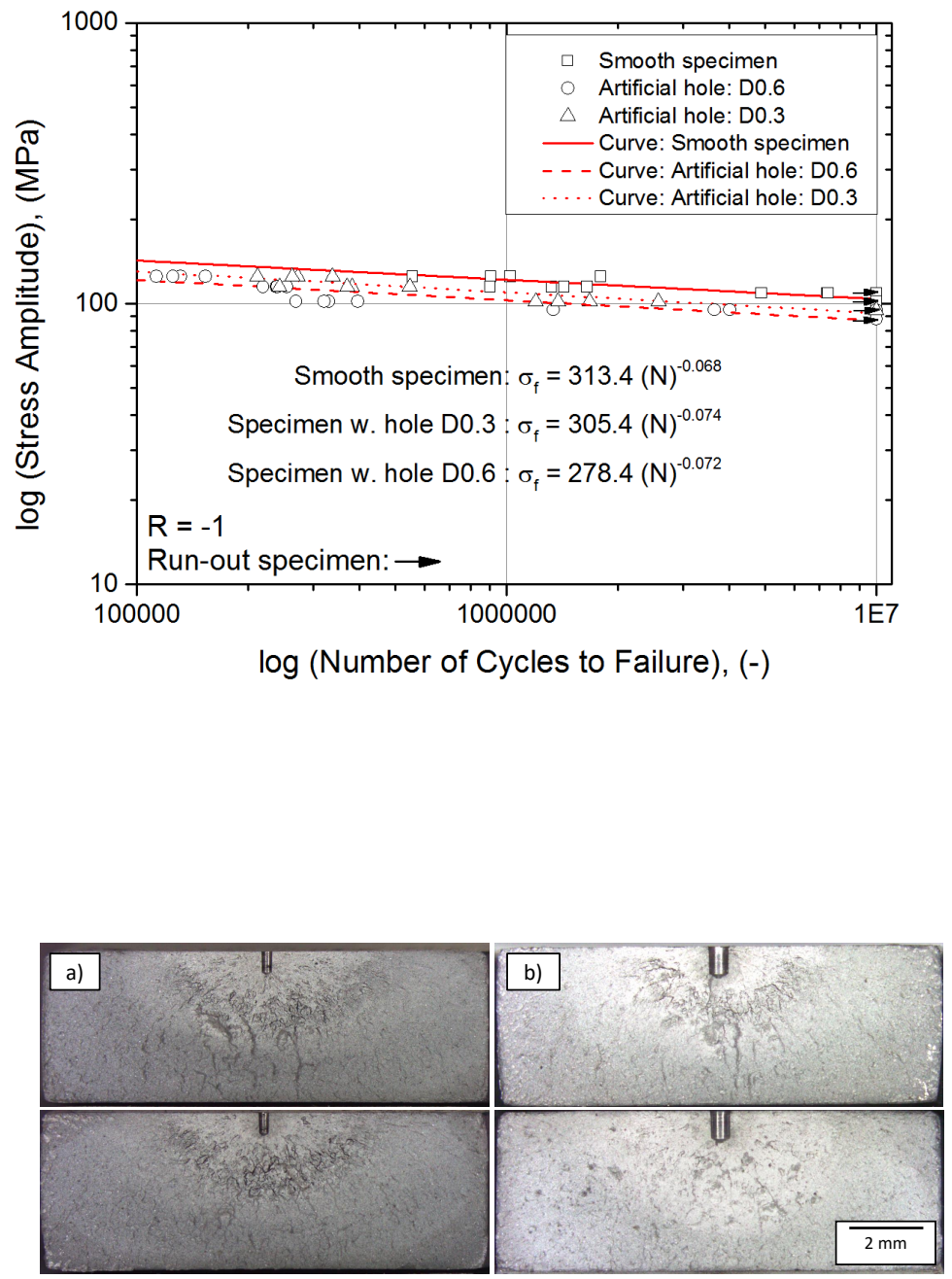

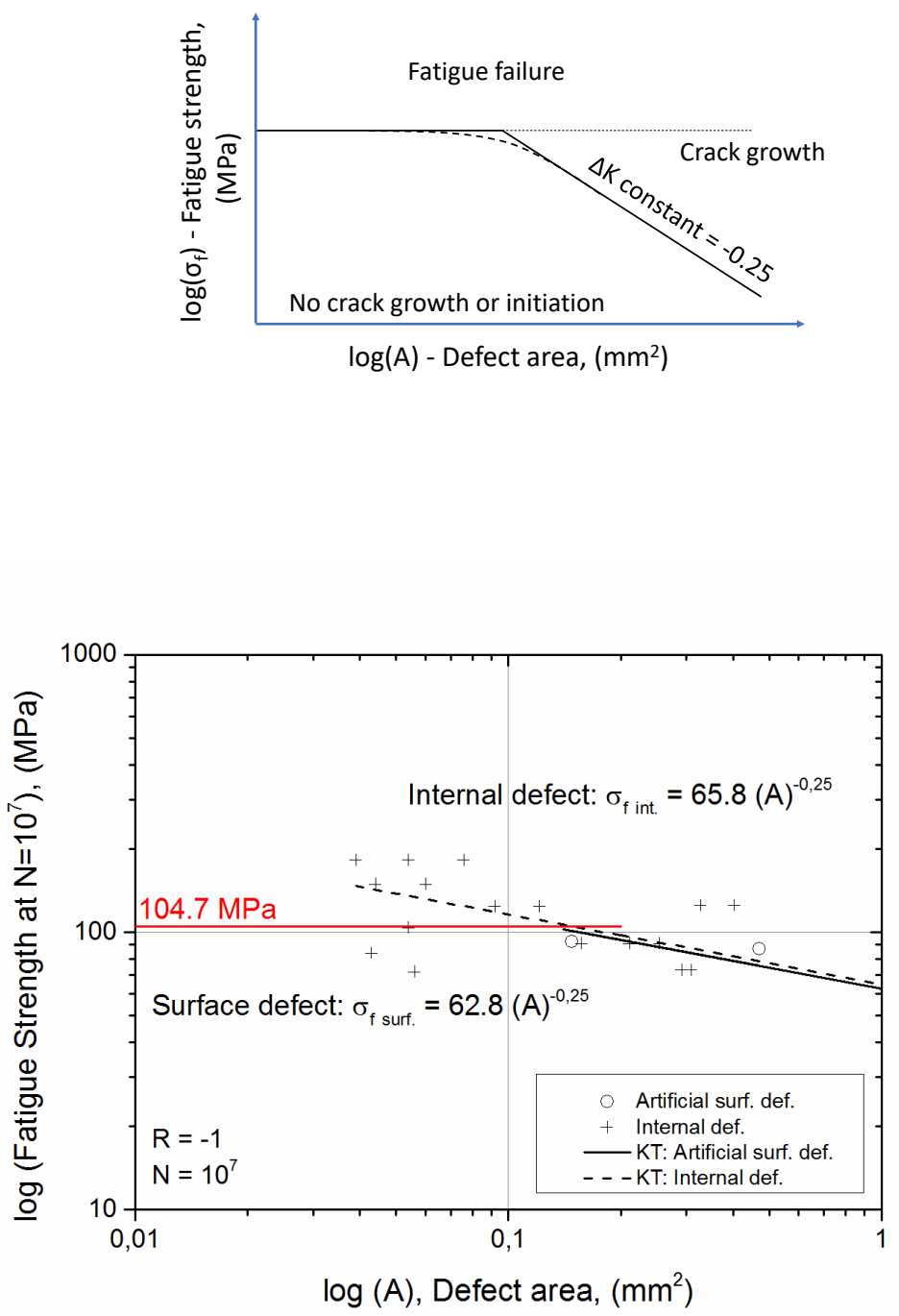